DOI:10.24193/tras.59E.1

Published First Online: 2020/02/27

\title{
I LIKE MY LEADER; NOT YOURS!
}

\author{
Aykut ARSLAN \\ Serdar YENER
}

\section{Aykut ARSLAN (corresponding author)}

Associate professor, Department of International

Business Management, Faculty of Economics and

Administrative Sciences,

Piri Reis University, Istanbul, Turkey

Tel.: 0090-216-581.0050-1536

E-mail: aarslan@pirireis.edu.tr

\section{Abstract}

Organizations depend on the output of their employees to attain their organizational goals through sustainable competitive advantage. Individuals' outcomes are an indicator of this. Thus, contextual factors may be directly or indirectly related to employee performance. One of these factors is leader-follower cultural fit. Considering that a leader can also shape the organizational culture, the fit between the leader's and his/ her followers' values can be transformed into a high-performance outcome. Since personal values are shaped by one's culture of origin, employees who observe, assess, and judge their leader according to their own values reflect on how congruent their perceived values are with those of their leader and act accordingly. By utilizing convenience sampling procedures, this research surveyed 202 full-time employees working in public institutions and organizations in Istanbul and its districts. The theoretical model was tested by moderated mediation analyses based on bootstrap methods. The research results revealed the collectivist traits of the region under analysis and indicate that individualistic tendencies may also be present. We found support to our theoretical model.

Keywords: paternalistic leadership, Turkey, Hofstede, culture, sub-cultures, performance.

\section{Serdar YENER}

Associate professor, Department of International Business and Trade, Faculty of Economics and Administrative Sciences, Sinop University, Sinop, Turkey

Tel.: 0090-368-333.0014-5059

E-mail: serdaryener@sinop.edu.tr 


\section{Introduction}

What kind of leaders influence followers? Or which leader influences which follower? Several studies have sought to identify what kind of leaders influence followers and whether certain leaders have an effect on specific followers (i.e., Li et al., 2017). While classifying leadership styles, studies often claim that certain types of leadership characteristics (i.e., transformational leadership) can be more influential (Mason et al., 2014; Leong and Fischer, 2011). However, it is clear that not every employee is affected at the same level, and factors such as context, personality traits and mental condition may reduce or increase such influence (Leong and Fischer, 2011; Campbell et al., 1993; Li et al., 2017). One of the arguments put forward in recent research (i.e., Bedi, 2019) is that every culture has its own leadership pattern, and that employees can be more effective under certain types of leaders. As every culture does not exhibit a uniform characteristic and each society has embedded ethnic elements and subcultures within its own culture, each subculture can also have a distinct leadership pattern. In line with this assertion, this research is based on the assumption that employees from different cultural backgrounds in Turkish employment settings have different reactions to the paternalistic leadership style that is claimed to be the favorite of Middle Eastern and Asian employees.

To contribute to this vein of leadership-culture literature, in addition to the aforementioned theories we base our theoretical assumption on Mobasseri et al.'s (2019) 'cultural fit' theory. The authors distinguish their description of cultural fit from the others and explain this phenomenon with two dimensions: cognition and behavior. Cognition is an extension of 'mental representations, beliefs, and values that individuals draw upon to make sense of their everyday experiences', and the behavior is represented as 'the norms and expectations that circumscribe individuals' actions' ( $p$. 4 ); in other words, it is individual's degree of compliance with the group's normative behavioral expectations. Due to the cultural proximity, followers see how their leaders are close to or resemble to their mental representations, beliefs and values; thus, they make sense and act upon. This sense-making steer them to behave within the boundaries of cultural norms and general expectations such as showing respect, and buttoning up one's jacket when confronting the manager or listening in silence with fear of interrupting, etc. By drawing on Goffman's (1959) analogy, they argue people can make inferences about others' backstage cognition through observing their frontstage behavior. But more importantly, those inferences are usually based on the observer's own backstage cognition. If cognition and behavior are not aligned, it is possible that people might develop incorrect perceptions and assume cultural unfit. Moreover, under the theory of basic human values, Schwartz (2012) highlights both common values in distinct cultures and individual differences due to personal priorities and hierarchy. According to this perspective, social culture can shape individuals' value judgments, while individual values can also affect social cultures and can lead to a slow change (Morris and $\mathrm{Fu}, 2001$ ). Recent research reflects the growing interest 
in values reflected within organizations by leaders who are very effective in shaping the organizational culture, how employees perceive these values, and to what extent they fit with employees' own values (Aycan, 2008; Brown and Trevino, 2009). Aycan (2008) refers to paternalistic leadership as an appropriate type of leadership to achieve effective and productive results in a collectivist society.

Turkey is considered as a collectivist country by many sources (e.g., Pellegrini and Scandura, 2006; Aycan, 2008; Gurbuz et al., 2018; Bedi, 2019). However, it has been proven that social cultures are not homogeneous, even within themselves, and they can be influenced by subcultures (Hofstede, 2001). Indeed, there are differences in the value judgments of people of Eastern and Western cultures, as has been observed among the Turkish people both by Turkish and non-Turkish researchers (Göregenli, 1995; Hofstede, 2001; Ayçiçeği-Dinn and Caldwell-Harris, 2013; Arpaci and Baloğlu, 2016). Similarly, Hofstede's 6-D model of national culture (Hofstede, 2001) reported Turkey's collectivism score within 33-41 band (Hofstede, undated). In other words, it varies from minimum 33 to maximum 41. For power distance, the score varies from minimum 62 to maximum 67; for masculinity it varies from minimum 43 to maximum 47; for uncertainty avoidance, the score varies from minimum 83 to maximum 88; and lastly, for long term orientation, the score varies from minimum 1 to maximum 86. All those minimum-maximum scores indicate likelihood of sub-cultures embedded in the dominant culture. The literature reports similar findings regarding the variety of sub-cultures (e.g., Triandis and Gelfand, 1998; Green et al., 2005; Taras et al., 2010; Eringa et al., 2015), and thus, Hofstede's model was criticized on this due to its manifestation of cultures mostly by their mean scores as if only one culture is existing.

According to the research on collectivist and individualist societies (Shavitt et al., 2011), the vertical and horizontal aspects of collectivist societies, which differ between the poles of status/hierarchy and equality, may have an impact on performance. Previous studies have reported different results on the relationship between the paternalistic leadership style and performance. Here, in this study, in accordance with cultural fit theory of Mobasseri et al. (2019), the model integrates both the mainstream culture and the subculture (through the vertical and horizontal characteristics of a collectivist society) such that depending on the followers' perception of cultural fit, it tries to find out a difference in the acceptance of paternalistic leadership and how it leads to an increase in the contextual performance. Additionally, it is observed that most of leadership studies are originated in Western culture. The impact of national culture on influencing leadership attributes and effectiveness is still in its infancy (Gu et al., 2015) and deserves further well-established studies. Lastly, in a Gallup survey in 2015, 50\% of the 2,700 workers surveyed reported their managers as the most significant reason for leaving their jobs (Snyder, 2015). Thus, investigating the leadership in organizational contexts are still worth to study. 


\section{Theoretical background and hypotheses}

By referring to seminal studies, Mobasseri et al. (2019, p. 13) argue that the organizational research conceptualizes cultural fit as 'the individuals' acting in ways that conform to normative expectations defined by the shared beliefs, assumptions, and values of organizational members. On the other hand, corporate culture in institutionalized organizations and organizations with a strong vision serves as the glue that holds all employees at all levels together in a common objective and future goal. Individuals try to comply with this common culture and values, and the extent to which they comply can bolster their professional success. Sometimes, however, strong and charismatic leaders may seek to redesign the corporate culture in alignment with their goals and objectives (Wilderom et al., 2012). An important factor in this setting is how much followers believe in, adapt to, and are inspired by the leader's vision. The most important determinant of the organizational culture is often its leader; however, other leaders may also emerge from that culture (Jung and Avolio, 1999; Sarros et al., 2002; Wilderom et al., 2012). Thus, leader-follower cultural fit is as important as the corporate and leader culture in terms of high performance (Wilderom et al., 2012). This 'fit' concept has also been discussed, rather indirectly, in two papers with two different approaches. Firstly, Hudson (2013) bases his assumptions on the attachment theory, and asserts that 'a good leader-follower relationship brings meaning and value to the follower's work; provides the follower with protection from undue risk and uncertainty that may arise in problem-solving, innovation, and creativity; and lessens the follower's stress associated with competitive pressures'. Likewise, Gu et al. (2015, p. 516) argue this issue in accordance with identity theory, and claim that 'employee identification with leader is a follower's relational self-based on close relations with the leader, which is different from a follower's collective self (referred to as social identity) based on the group or organization membership and identification'. Further, they analyze this identification with the leader in two different ways: 'One evokes a subordinate's self-concept in the recognition that he or she shares similar values with the leader, the other gives rise to a subordinate's desire to change his or her self-concept so that his or her values and beliefs become more similar to that of the leader' ( $\mathrm{p}$. 516). When employees' jobs in a workplace are closely linked, they are more likely to be influenced by each other's and their leader's behaviors (Adkins and Russell, 1997). Individuals in a work setting where such close relationships are established, experience respect for and confidence in their leaders (Becker, 1992). An employee who thinks he or she is working with a leader who fits with his personal and cultural values considers his or her leaders' expectations for work within the framework of value congruence and strives to meet these expectations (Greenberg, 1990).

\subsection{The relationship between paternalistic leadership and contextual performance}

A behavioral and an outcome aspect must be distinguished for the definition of performance (Campbell et al., 1993). Behavioral performance refers to an individual's acts 
that serve the goals of his or her organization. The outcome aspect of performance refers to the results of an individual's behaviors. For example, the work of a retailer in the field is related to his or her behavioral performance, while the sales figures constitute the outcome aspect of performance (Campbell et al., 1993). As behaviors and outcomes are not seen at the same time in organizations, performance evaluation is difficult. Thus, Borman and Motowidlo (1993) point out that total performance is determined by two sub-dimensions, including task performance and contextual performance, and indicate psychological and sociological factors as the determinants of contextual performance. Task performance refers to an employee's direct (e.g., production department) and indirect (e.g., management and support staff) contributions to the goods and services in his or her organization. Contextual performance refers to the social and psychological setting created by employees working in the production of goods and services, although they do not directly contribute to the goods and services provided.

Previous research indicates congruence as an indicator of performance and member values as an indicator of congruence (Glew, 2012). Values have a decisive influence on performance, as they affect behavior (Schwartz, 2012). This is also regarded as the origin of value congruence (Lamm et al., 2010). Norms are the point of reference of values, and the reasons for individual behavior are based on norms set through values (Kant, 1997). In this regard, behaviors considered to be the determinants of performance serve as a source of motivation (Schwartz, 2012), and reflect the culture in which norms are developed as one of the most important determinants of values (Bicchieri, 1990). Many studies have revealed that norms developed according to the characteristics of cultures in which people live are the source of motivation for behavior through their values (Nordlund, 2009; Schwartz, 2012).

Paternalistic leadership, addressed in culturally oriented leadership studies, is accepted as a type of leadership with a heightened awareness of social norms (Mansur, 2016). Paternalistic leadership refers to a leader's father-like behaviors towards his followers, such as protection, guidance, the satisfaction of needs, and problem solving, which are demonstrated by a family leader within the influence of social norms in patriarchal societies (Bedi, 2019). Paternalistic leadership behavior in collectivist societies is associated with high hierarchical relationships and strong family and interpersonal relationships (Aycan, 2008; Bedi, 2019). Uhl-Bien and Maslyn (2005) define paternalistic leadership as an authoritarian form of leadership with a coercive character that conforms to theory $\mathrm{X}$ management style, and frame it on a totally pragmatic basis within which a superior expects subordinates to achieve high performance. In the existing literature, paternalistic leadership is often characterized by three dimensions: authoritarianism, benevolence and morality. However, instead of a rigid definition of authority, the field research points out that subordinates or followers voluntarily accept their leader's protection and control for their own sake (Pellegrini and Scandura, 2006). Similarly, Aycan and Kanungo (1998) investigate the negative correlation between paternalistic leadership and authoritarianism, and perceive such leadership as an interaction in which employees are also active and supported rather than a unilateral process in which only the leader is active and dominant. Aycan (2008) claims that difficulty regarding communication in 
collectivist societies with a high-power distance can be resolved through interaction and reciprocity of behaviors based on paternalistic leadership. A high-power distance results from power inequality, and this power arises from the status of individuals in collectivist societies. The negative aspect of this power to isolate individuals is avoided through paternalistic leader's benevolent, protective, and caring behaviors.

In collectivist societies, the leader of an organization or society is perceived as an officer who protects, looks after, and guides individuals as long as they demonstrate loyalty and obedience. Considering the determinants of performance within the theory of value congruence, a high level of congruence between the cultural values of an organization driven by paternalistic leadership behaviors and the values employees derive from collectivist cultures can lead to an increase in contextual performance that positively affects overall performance. In light of these arguments, the following hypothesis is proposed:

$\mathbf{H}_{1}$ Paternalistic leadership positively predicts employees' contextual performance.

\subsection{The relationship between paternalistic leadership and horizontal and vertical individualist and collectivist tendencies}

Even some societies classified as individualist and collectivist do not demonstrate homogeneous behaviors, and can be distinguished as horizontal (valuing equality) and vertical (emphasizing hierarchy) societies (Nelson and Shavitt, 2002).

The distinction between horizontal and vertical individualist and collectivist culture is based on Hofstede's (2001) definition of power distance in communities. Power distance is divided into low and high-power distance cultures, and further grouped into four different categories within individualist and collectivist societies.

Individuals' values regarding competition, success and power in vertical individualist societies differ from the egalitarian values of individuals satisfied with a basic welfare level in horizontal individualist societies. In addition, individuals in vertical collectivist societies put the overall benefit of their organization above their personal benefits, show respect for the organizational authority, and act according to their values. These individuals represent the status and prestige of the family, organization, and community to which they belong and behave accordingly (Shavitt et al., 2011). On the other hand, horizontal collectivist societies place great emphasis on individuals' sense of interdependence, cooperation, and solidarity and the survival of the organization (Gannon, 2001).

Considering the cultural norms of the collectivist society in light of the assertions above, paternalistic leadership can be influential on the horizontal and vertical behavior tendencies of collectivist societies through protection, preservation, and help and guidance behaviors (Aycan, 2008) by taking into account social balance. Accordingly, we propose the following:

Paternalistic leadership has a positive and significant effect on employees with horizontal-vertical collectivist tendencies $\left(\mathbf{H}_{2 \mathrm{a}}\right)$, but negative and significant effect on employees with horizontal-vertical individualist tendencies $\left(\mathbf{H}_{2 \mathrm{~b}}\right)$. 


\subsection{The mediating role of horizontal and vertical individualist and collectivist tendencies}

The determining role of culture in the emergence of performance requires that leadership behaviors be culturally focused within collectivist societies (Brodbeck et al., 2004). The level of employee performance that organizations in collectivist societies need in order to attain their goals can be achieved by paternalistic leadership behaviors that are congruent with the cultural values of individuals (Aycan, 2008). Different results in various studies on parental leadership behavior (Uhl-Bien and Maslyn, 2005; Aycan, 2008; Pellegrini and Scandura, 2006) suggest that paternalistic leadership exerts an influence on the organization through diverse mediating variables. Although there are individualist people in collectivist societies, horizontal and vertical tendencies emerging with sub-values differentiated under collectivism can lead to the mediation effect of paternalistic leadership. Pellegrini and Scandura (2006) suggest this example seen in collectivist societies for the US, representing the characteristics of an individualist society. In an organization in an individualist society like the US, employees who sometimes display collectivist traits can work efficiently through the value congruence with paternalistic leaders, contrary to the general trend (Pellegrini and Scandura, 2006). In a collectivist culture like Turkey, vertical and horizontal differentiation can occur in organizations, and individualist tendencies can arise even in a collectivist organization.

The dominant culture is defined as a culture that dominates the majority of a society, and it exhibits subcultures formed by individuals who share common values under the dominant culture but do not pose a threat to the dominant culture. The emphasis on the social and psychological climate in the definition of contextual performance suggests that subcultures play a mediating role, since they are formed by individuals who differ in terms of experiences, feelings, thoughts, and behaviors in the dominant culture. Social and psychological similarities play an active role in the formation of subcultures. Behaviors of individuals who share the subculture do not pose a threat to the dominant culture, but rather increase the productivity of organizations if they are tolerated (Tushman and O'Reilly, 1997). As long as subcultures in collectivist or individual societies do not negatively affect the overall objectives and dominant culture of the society, they can lead to an increase in performance; thus, subcultures should be supported to increase productivity (Khatib, 1996).

If individualist tendencies in collectivist societies or horizontal and vertical tendencies in collectivist-individualist societies are accepted as subcultures, they can play a mediating role in the relationship between paternalistic leadership and performance. In light of these arguments, the following hypotheses are proposed:

Horizontal-vertical collectivist $\left(\mathbf{H}_{3 \mathrm{a}}\right)$ and horizontal-vertical individualist $\left(\mathbf{H}_{3 \mathrm{~b}}\right)$ variables play a mediating role between paternalistic leadership and contextual performance. 


\section{Methods}

\subsection{Sample}

Participants were civil servants from Istanbul and its districts, either working in local governments or in local agencies of central government institutions. Istanbul, as one of the biggest metropolitan cities in the world, and as being the biggest city of Turkish Republic, hosts a melting pot of citizens from almost everywhere in Anatolia. Considering the multi-cultural mosaic of the city, it would not be wrong to think that civil servants working here are coming from everywhere in Turkey and representing their ethnical and sub-cultural clues.

Women composed $32.7 \%$ of the sample, and $67.3 \%$ were men. Among the respondents, $55 \%$ have been working for 0-5 years, $44.6 \%$ for 6-10 years, and one person for 11-15 years. $29.7 \%$ are married and $70.3 \%$ are single. $45.5 \%$ have a high school/vocational high school degree, $49 \%$ have a bachelor's degree, $4.5 \%$ have a master's degree, and $1 \%$ has a doctorate's degree. The age of the participants ranges from 18 to 49 .

Table 1: Sample's characteristics

\begin{tabular}{|c|c|c|}
\hline Variable & Frequency & $\%$ of total \\
\hline \multicolumn{3}{|l|}{ Gender } \\
\hline Male & 136 & 67,3 \\
\hline Female & 66 & 32,7 \\
\hline \multicolumn{3}{|l|}{ Age distribution (years) } \\
\hline $18-25$ & 9 & 4,5 \\
\hline $26-33$ & 100 & 49,5 \\
\hline $34-41$ & 89 & 44,1 \\
\hline $42-49$ & 4 & 2,0 \\
\hline \multicolumn{3}{|l|}{ Marital Status } \\
\hline Married & 60 & 29,7 \\
\hline Single & 142 & 70,3 \\
\hline \multicolumn{3}{|l|}{ Level of education } \\
\hline $\mathrm{PhD}$ & 2 & 1,0 \\
\hline Master's Degree & 9 & 4,5 \\
\hline University degree & 99 & 49,0 \\
\hline Higher school education & 92 & 45,5 \\
\hline \multicolumn{3}{|l|}{ Work Experience } \\
\hline $0-5$ yrs & 111 & 55,0 \\
\hline $6-10$ yrs & 90 & 44,6 \\
\hline $11-15 \mathrm{yrs}$ & 1 & 0,5 \\
\hline \multicolumn{3}{|l|}{ Position } \\
\hline Managerial positions (top. - middle) & 9 & 4,5 \\
\hline Employees & 193 & 95,5 \\
\hline
\end{tabular}




\subsection{Measures}

Although collectivism and individualism are accepted as two distinct cultural patterns, Triandis and Gelfand (1998) argued that there are many variations of collectivism and individualism. To measure these distinctions, they suggested to coin the horizontal and vertical relationships. This could help researchers to find how an individual sees himself in a culture where he is living. When asking 'what you have in common with your family and friends' or 'what makes you different from your family and friends' (Trafimow et al., 1991) researcher could get answers whether the person sees himself either as one of them or different from them. And for this purpose, the authors employed the horizontal and vertical individualism and collectivism scale to find the same among the civil servants.

The items on all scales were rated on 5-point Likert scales ranging from 1 = strongly disagree to $5=$ strongly agree. The reliability and validity statistics are presented in Table 2 . The validity measured by KMO and Bartlett's test of sphericity seems within the acceptable ranges for all the scales. The total variance explained for paternalistic leadership questionnaire is $73.90 \%$; for the horizontal and vertical individualism and collectivism scale is $60.94 \%$, and lastly for the contextual performance scale is $58.77 \%$. Unexpectedly, the horizontal and vertical individualism and collectivism scale did not yield four factors as proposed by Özbek (2010). There are some studies which report inconclusive results regarding the number of factors (Wasti and Erdil, 2007) but still, with two factors, we continued to perform the analyses.

\subsubsection{Paternalistic leadership questionnaire (PLQ)}

Aycan et al.'s (2013) 10-item questionnaire was employed in the research. A sample item is thus: 'The ideal leader creates a family environment in the workplace.'

\subsubsection{Horizontal and vertical individualism and collectivism scales}

Two separate 8-item scales originally developed by Singelis et al. (1995) and later modified by Triandis and Gelfand (1998) were used in the research. The scales were translated into Turkish by Özbek (2010). A sample item on the individualism scale is thus: 'Winning is everything.' A sample item on the collectivism scale is thus: 'Parents and children must stay together as much as possible.'

\subsubsection{Contextual performance scale}

The contextual performance scale, developed by Jawahar and Carr (2007), was used to measure contextual performance. A sample item on the scale is thus: 'I perform my duties with extra special care.' 


\subsection{Data collection}

From June 21 to August 3, 2018, both authors contacted with their networks in three biggest online forums of civil servants ${ }^{1}$. The contacts were asked to find volunteers to fill in an online Google survey. A total of 221 questionnaires were returned out of which 19 were extracted due to missing data or other reasons; therefore, in total 202 valid questionnaires ware used. SPSS Statistics 23 software and PROCESS macro version 3.1 were used for data analysis. Figure 1 presents the research model.

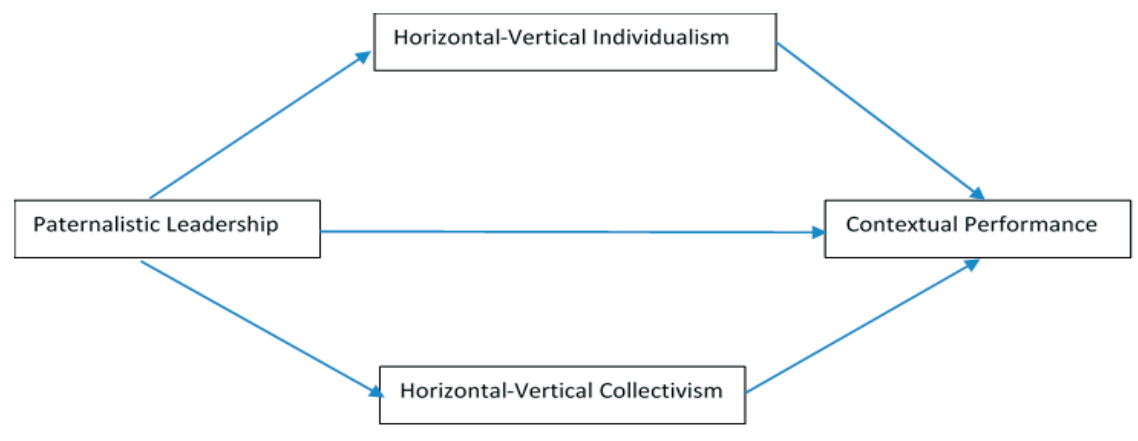

Figure 1: Research model

\section{Results}

The psychometric properties of the scales are shown in Table 2. Accordingly, the suitability of the sample is satisfactory for all measuring instruments. However, the culture scales yielded a one-factor structure in contrast to the two-factor structure proposed in the existing literature.

Table 2: Analysis of the results regarding the research scales

\begin{tabular}{lcccc}
\hline \multicolumn{1}{c}{ Test } & PLQ & $\begin{array}{c}\text { Individualism } \\
\text { Scale }\end{array}$ & $\begin{array}{c}\text { Collectivism } \\
\text { Scale }\end{array}$ & $\begin{array}{c}\text { Contextual } \\
\text { Performance Scale }\end{array}$ \\
\hline $\begin{array}{l}\text { KMO Measure and Bart- } \\
\text { lett's Test of Sphericity }\end{array}$ & $0.75(p<0.000)$ & $0.82(p<0.000)$ & $0.81(p<0.000)$ \\
$\begin{array}{l}\text { Number of Factors and } \\
\text { Total Variance Explanation }\end{array}$ & 2 Factors & 2 Factors & One Factor \\
Rate by Factor Loads & $73.90 \%$ & \multicolumn{2}{c}{$60.94 \%$} & $58.77 \%$ \\
Reliability Results & $\alpha=0.91$ & $\alpha=0.96 \quad \alpha=0.68$ & $\alpha=0.87$ \\
\hline
\end{tabular}

Prior to hypothesis testing, Pearson's correlation coefficients were calculated (Table 3). A moderate positive correlation is observed between employees' contextual performance and perceived paternalistic leadership $(r=0.38 ; p<0.000)$. There is no correlation between employees' contextual performance and horizontal-vertical in-

1 These websites are: https://memurunyeri.com/forum/index.html, https://forum.memurlar.net/, https:// www.memurlar.net/. 
dividualist tendencies $(r=-0.03 ; p>0.05)$. There is also a high positive significant correlation between employees' contextual performance and their horizontal-vertical collectivistic tendencies $(r=0.71 ; p<0.000)$. As predicted, there is a moderate negative correlation $(r=-0.56 ; p<0.000)$ between perceived paternalistic leadership and horizontal-vertical individualist tendencies, while the perceived paternalistic leadership of employees displaying horizontal-vertical collectivistic tendencies indicates a low but positive correlation $(r=0.26 ; p<0.000)$.

Table 3: Mean, standard deviation, and correlation values of variables

\begin{tabular}{lcccccc}
\hline \multicolumn{1}{c}{ Variables } & $M$ & $S D$ & 1 & 2 & 3 & 4 \\
\hline 1-Contextual Performance & 3.74 & 0.74 & 1 & & & \\
2-Paternalistic Leader & 3.28 & 0.76 & $0.38^{* *}$ & 1 & & \\
3-VH Individualist & 3.01 & 1,10 & -0.03 & $-0.56^{* *}$ & 1 & \\
4-VH Collectivist & 3.00 & 0.53 & $0.71^{* *}$ & $0.26^{* *}$ & 0.15 & 1 \\
\hline
\end{tabular}

$N=202, * * p<0.000$

The PROCESS module version 3.1, developed by Hayes (2018) as an add-on for SPSS, was used for hypothesis testing. A mediation analysis was performed within Model 4 with 5000 bootstrapped samples.

Employees' perceived paternalistic leadership positively predicts their contextual performance $(\beta=0.360, p<0.000)$. Thus, $H_{1}$ is accepted. Paternalistic leadership has a negative and significant effect on employees with horizontal-vertical individualist tendencies $(\beta=-0.680, p<0.000)$. On the other hand, paternalistic leadership has a positive and significant effect on employees with horizontal-vertical collectivist tendencies $(\beta=0.180, p<0.000)$; thus, both $\mathrm{H}_{2 \mathrm{a}}$ and $\mathrm{H}_{2 \mathrm{~b}}$ are accepted. According to the analysis of the mediation effects, the horizontal-vertical collectivist tendency has a significant effect $(\beta=0.876, p<0.000)$; this is also true for the horizontal-vertical individualist tendency but the unstandardized coefficient seems small $(\beta=0.093, p>0.000)$.

Table 4: Results of the mediation analysis

\begin{tabular}{|c|c|c|c|c|c|c|c|c|c|c|c|c|}
\hline \multirow{2}{*}{$\begin{array}{c}\text { Antecedent } \\
\text { Variable }\end{array}$} & & \multicolumn{3}{|c|}{$\mathrm{M}_{1}(\mathrm{VH}-\mathrm{Ind})$} & \multicolumn{4}{|c|}{$\mathrm{M}_{2}(\mathrm{VH}-\mathrm{Coll})$} & \multicolumn{4}{|c|}{ Y (ConPerf) } \\
\hline & & Coeff. & SE & $p$ & & Coeff. & $S E$ & $p$ & & Coeff. & $S E$ & $p$ \\
\hline $\mathrm{X}(\mathrm{PL})$ & $a_{1}$ & -0.68 & 0.071 & $0.000^{* *}$ & $a_{2}$ & 0.18 & 0.050 & $0.000^{* *}$ & $c^{\prime}$ & 0.265 & 0.056 & $0.000^{* *}$ \\
\hline$M_{1}(\mathrm{VH}-\mathrm{Ind})$ & & - & - & - & & - & - & - & $b_{1}$ & 0.093 & 0.047 & $0.048^{*}$ \\
\hline $\mathrm{M}_{2}(\mathrm{VH}-\mathrm{Coll})$ & & - & - & - & & - & - & - & $b_{2}$ & 0.876 & 0.070 & $0.000^{* *}$ \\
\hline Constant & $i_{\mathrm{M} 1}$ & 5.243 & 0.238 & $0.000^{* *}$ & $i_{\mathrm{M} 2}$ & 2.405 & 0.158 & $0.000^{* *}$ & $i_{Y}$ & -0.03 & 0.309 & 0.923 \\
\hline & & \multicolumn{3}{|c|}{$R^{2}=0.317$} & \multicolumn{4}{|c|}{$R^{2}=0.069$} & \multicolumn{4}{|c|}{$R^{2}=0.546$} \\
\hline & & \multicolumn{3}{|c|}{$F(92.837)=200.000, p<0.000^{* *}$} & \multicolumn{4}{|c|}{$F(14.754)=200.000, p<0.000^{* *}$} & & \multicolumn{3}{|c|}{$F(79.349)=198.000, p<0.000^{* *}$} \\
\hline
\end{tabular}

$* *<0.000, *<.05$

$N=202$, Confidence Interval \%95, Bootstrap Resampling Size 5000, Total Effect $(c)=0.360, R^{2}=0.130$;

$\mathrm{F}_{33.087}=200.000, p<0.000$

PL: Paternalistic Leadership, VH-Ind: Vertical-Horizontal individualist, VH-Coll: Vertical-Horizontal Collectivist,

ConPerf: Contextual Performance 
Although the Sobel test is used for testing the significance of a mediation effect in the current literature, research results show that the interpretation of indirect confidence intervals obtained by bootstrapping is more significant in light of the new statistical methods (Hayes, 2018, p. 201).

Additionally, what accounts more is that if the sampling distribution of the mediated effect is skewed away from 0, this reveals the power of bootstrap tests (Hayes, 2018). Thus, we run a bootstrapping test with 5000 samples and looked at the upper and lower bounds of the confidence intervals (see Table 5). For the variable of horizontal-vertical individualist tendency, the true total indirect effect is $95 \%$ likely to range from 0.0008 to 0.1823 - the estimated effect is 0.093 (lying in between these two values). If zero does occur between the LLCI (Low limit confidence interval) and the ULCI (Upper limit confidence interval) then we can conclude that the total indirect effect is significant. Following the same procedure, for the horizontal-vertical collectivist tendency, we found the true total indirect effect is $95 \%$ likely to range from 0.0730 to 1.018 - the estimated effect is 0.876 (lying in between these two values). If zero does not occur between the LLCI and the ULCI then we can conclude that the total indirect effect is significant. Thus, it seems that both cultural tendency variables have a full mediation effect $\left(\mathrm{H}_{3 \mathrm{a}}\right.$ and $\mathrm{H}_{3 \mathrm{~b}}$ are accepted). For the first regression model given in Table 4, we found the following: (path $a_{1}$ ) $R^{2}=0.317 ; \mathrm{F}_{92.837}=200.000, p<0.000$. For the second regression model, we found the following: (path $a_{2}$ ) $R^{2}=0.069 ; \mathrm{F}_{14.837}=200.000$, $p>0.000$. For the third and last regression model, we found the following: (paths $b_{1}-b_{2}$ and $\left.c^{\prime}\right) R^{2}=0.546 ; \mathrm{F}_{79.349}=200.000, p<0.000$. Thus, in the first model, paternalistic leadership, accounts for $32 \%$ of the variance in the mediating variable (horizontal-vertical individualist). In the second model, paternalistic leadership accounts for $1 \%$ of the variance in the mediating variable. It is clear that, in the last model, two mediating variables significantly account for $55 \%$ of the variance in the independent variable and employees' contextual performance.

Table 5: The indirect effect of the independent variable on the dependent variable according to the results of the bootstrap analysis

\begin{tabular}{lcccc}
\hline & Effect & SE & LLCl & ULCl \\
\hline Total & 0.265 & 0.062 & 0.144 & 0.387 \\
HV individualist & 0.093 & 0.047 & 0.0008 & 0.182 \\
HV collectivistic & 0.876 & 0.074 & 0.730 & 1.018 \\
\hline
\end{tabular}

Unstandardized results; SE=Standard Error; LLCI=Low limit confidence interval; ULCI=Upper limit confidence interval

\section{Discussion and conclusion}

In parallel with other studies (e.g., Kağıtçıbaşı, 1997; Green et al., 2005; AyçiçeğiDinn and Caldwell-Harris, 2013), the research results also reveal the collectivist traits of the region under analysis, and indicate that individualist tendencies may also be present. Additionally, these studies argued individuals living in more modernized and 
high-income parts of collectivist societies may show individualist behaviors. Turkish families with high-income and some with well-education background want more autonomy for their children compared to the low-income ones (Kağıtçıbaşı and Ataca, 2005). This may even result in cultural conflict in the same society and social philosophers wanted to find answers on how a social order could be established. Some researchers go even further to claim that it is not that easy to differentiate societies as collectivist-individualist, and it is possible that some people may be an individualist and a collectivist at the same time (Green et al., 2005, p. 322). Green et al. (2005) argue from a social psychological perspective, and attribute the reasons to social contexts and social relations. A person can demonstrate individualist tendencies at work while his/her collectivist traits may be more prominent at home among family members.

On the other hand, leaders with individualist behaviors may be seen distant and unfit by followers who have collectivist tendencies (Caza and Posner, 2014). Paternalistic leadership behavior is a process of mutual interaction and voluntary acceptance, as pointed out by Pellegrini and Scandura (2006), rather than a coercion and imposition, as proposed by Uhl-Bien and Maslyn (2005). The results also confirm that a leader may have a crucial effect on collectivist members more than the individualist ones (Aycan, 2008). Additionally, as it was stated in Kağıtçıbaşı's (1997) study, Turkish followers value leaders who ask about their personal stuff, family issues, children, problems; i.e. common behaviors of collectivist individuals. The research has also revealed that the sensitivity to psychological and sociological factors determining contextual performance can be predicted by paternalistic leadership, and that paternalistic leadership can be influential, especially among employees with collectivist tendencies. Thus, the performance that will enable organizations to achieve their goals requires sensitivity to the cultural characteristics of the society.

According to the research results, both individualist and collectivist tendencies have a different mediation effect on paternalistic leadership behaviors. This result implies that a leader should devote some attention to sub-cultural differences. With the increase of globalization, multicultural workplace settings are now more common. Given that cultures increasingly differ in their every segment, not only in Turkey but also in many parts of the world, managers and leaders who have expectations for the behavioral outcome and total aspect of performance should consider it. Interaction, harmony and solidarity with followers are emphasized as the determinant of performance in many leadership approaches and theories (Aycan, 2008; Bedi, 2019; Niemeyer and Cavazotte, 2016). The research results have supported the positive effect of paternalistic leadership on collectivist cultural traits based on interpersonal interaction and solidarity. Thus, leaders should develop and exercise cultural awareness and consider the importance of interpersonal interaction and congruence. In parallel with this result, the study by Wasti et al. (2007) in Turkey highlights that cultural values, which are the source of motivation for behaviors, should be investigated at the individual level. The manifestation of individual differences raises awareness and can overcome problems related to congruence. 
The results of the present research have also confirmed Göregenli's (1995) claims that Turkey, as an example of an eastern culture, cannot be classified as a pure collectivist society. However, this research has yielded no horizontal and vertical separation, as claimed by research focused on Turkey using the individualism and collectivism scales (i.e. Özbek, 2010). Both this study and previous research (Wasti, 2007; Göregenli, 1995) support the claim that the perceived values of individuals who share the same socio-cultural setting can also vary by time and situation. Thus, leaders should be more sensitive of and compatible with their interpersonal relations and behaviors (Lamm et al., 2010). In conclusion, the recent increase in mass migration as a result of environmental wars and economic crises implies that individuals with different cultural tendencies will live together permanently in many societies previously thought to be homogeneous.

The study has some limitations. The surveys were applied at different times and at various intervals. However, they are open to bias because they were filled out based on self-report. Future studies can address the understanding of social values in order to improve performance and the effect of communication factors on the congruence process.

Additionally, the horizontal and vertical individualism and collectivism scale used for this study seems to have some psychometric problems with regards to its number of factors. Thus, it will be beneficial to use other measurement tools such as Singelis et al.'s (1995) original 32-item scale as well as other various 27 scales that measure individualism and/or collectivism (Oyserman et al., 2002). And lastly, along with contextual performance, task performance could also be added as another dependent variable.

\section{References:}

1. Adkins, C.L. and Russell, C.J., 'Supervisor-Subordinate Work Value Congruence and Subordinate Performance: A Pilot Study', 1997, fournal of Business and Psychology, vol. 12, no. 2, pp. 205-218.

2. Arpaci, I. and Baloğlu, M., 'The Impact of Cultural Collectivism on Knowledge Sharing among Information Technology Majoring Undergraduates', 2016, Computers in Human Behavior, vol. 56, pp. 65-71.

3. Aycan, Z. and Kanungo, R.N., 'Paternalism: Towards conceptual refinement and operationalization', in Kim, U., Yang, K.S. and Hwang, K.K. (eds.), Indigenous and Cultural Psychology: Understanding People in Context, New York, NY: Springer, 1998, pp. 445-466.

4. Aycan, Z., Schyns, B., Sun, J., Felfe, J. and Saher, N., 'Convergence and Divergence of Paternalistic Leadership: A Cross-cultural Investigation of Prototypes', 2013, Journal of International Business Studies, vol. 44, no. 9, pp. 962-969.

5. Aycan, Z., 'Cross-Cultural Approaches to Leadership', in Smith, P.B., Peterson, M.F. and Thomas, D.C. (eds.), The Handbook of Cross-Cultural Management Research, Thousand Oaks, CA.: Sage Publications, 2008, pp. 219-238.

6. Ayçiçeği-Dinn, A. and Caldwell-Harris, C.L., 'Vertical Collectivism, Family-consciousness and Urbanization in Turkey', 2013, Electronic Journal of Social Sciences, vol. 12, no. 47, pp. 232-251. 
7. Becker, T.E., 'Foci and Bases of Commitment: Are They Distinctions Worth Making?', 1992, Academy of Management fournal, vol. 35, no. 1, pp. 232-244.

8. Bedi, A., 'A Meta-Analytic Review of Paternalistic Leadership', 2019, Applied Psychology, doi:10.1111/apps.12186.

9. Bicchieri, C., 'Norms of Cooperation', 1990, Ethics, vol. 100, no. 4, pp. 838-861.

10. Borman, W.C. and Motowidlo, S.J., 'Expanding the Criterion Domain to Include Elements of Contextual Performance', in Schmitt, N. and Borman, W.C. (eds.), Personnel Selection in Organizations, San Francisco: Jossey-Bass, 1993, pp. 71-98.

11. Brodbeck, F.C., Hanges, P.J., Dickson, M.W., Gupta, V. and Dorfman, P.W., 'Societal Culture and Industrial Sector Influences on Organizational Culture', in House, R.J., Hanges, P.J., Javidan, M., Dorfman, P.W. and Gupta, V. (eds.), Culture, Leadership, and Organizations: The GLOBE Study of 62 Societies, Thousand Oaks, CA: Sage Publications, 2004, pp. 654-668.

12. Brown, M.E. and Trevino, L.K., 'Leader-Follower Values Congruence: Are Socialized Charismatic Leaders Better Able to Achieve It?', 2009, Journal of Applied Psychology, vol. 94, no. 2, pp. 478-490.

13. Campbell, D.J., Bommer, W. and Yeo, E., 'Perceptions of Appropriate Leadership Style: Participation versus Consultation across Two Cultures', 1993, Asia Pacific Fournal of Management, vol. 10, no. 1, pp. 1-19.

14. Caza, A. and Posner, B.Z., 'Growing Together: Evidence of Convergence in American and Singaporean Sources of Satisfaction with Leaders', Paper presented at Western Academy of Management Annual Meeting, Napa Valley, CA, 2014, [Online] available at http://www. leadershipchallenge.com/UserFiles/Growing\%20together-WAM\%202014.pdf, accessed on March 10, 2019.

15. Eringa, K., Caudron, L.N., Rieck, K., Xie, F. and Gerhardt, T., 'How Relevant are Hofstede's Dimensions for Inter-cultural Studies? A Replication of Hofstede's Research among Current International Business Students', 2015, Research in Hospitality Management, vol. 5, no. 2, pp.187-198.

16. Gannon, M.J., Understanding Global Cultures: Metaphorical fourneys through 23 Nations, $2^{\text {nd }}$ edition, Thousand Oaks, CA: Sage Publications, 2001.

17. Glew, D.J., 'Effects of Interdependence and Social Interaction-Based Person-team Fit', 2012, Administrative Sciences, vol. 2, no. 1, pp. 26-46.

18. Goffman, E., The Presentation of Self in Everyday Life, New York: Doubleday, 1959.

19. Göregenli, M., 'Kültürümüz Açısından Bireycilik-Toplulukçuluk Eğilimleri: Bir Başlangıç Çalışması' (Individualism and Collectivism Orientations in Our Culture: An Initial Study), 1995, Journal of Turkish Psychology, vol. 10, no. 35, pp. 1-14.

20. Green, E.G.T., Deschamps, J.C. and Páez, D., 'Variation of Individualism and Collectivism within and between 20 Countries: A Typological Analysis', 2005, Journal of Cross-Cultural Psychology, vol. 36, no. 3, pp. 321-339.

21. Greenberg, J., 'Looking Fair vs. Being Fair: Managing Impressions of Organizational Justice', in Staw, B.M. and Cummings, L.L. (eds.), Research in Organizational Behavior, Greenwich Ct.: JAI Press, 1990, pp. 111-157.

22. Gu, Q., Tang, T. and Jiang, W., 'Does Moral Leadership Enhance Employee Creativity? Employee Identification with Leader and Leader-member Exchange (LMX) in the Chinese Context', 2015, Journal of Business Ethics, vol. 126, no. 3, pp. 513-529. 
23. Gurbuz, S., Costigan, R. and Teke, K., 'Does Being Positive Work in a Mediterranean Collectivist Culture? Relationship of Core Self-evaluations to Job Satisfaction, Life Satisfaction, and Commitment', 2018, Current Psychology, doi: 10.1007/s12144-018-9923-6.

24. Hayes, A.F., Introduction to Mediation, Moderation, and Conditional Process Analysis: A Regression-Based Approach, $2^{\text {nd }}$ edition, New York: The Guilford Press, 2018.

25. Hofstede, G., Culture's Consequences: Comparing Values, Behaviors, Institutions and Organizations across Nations, Thousand Oaks, CA: Sage Publications, 2001.

26. Hofstede, G., '6D Model of National Culture', undated, [Online] available at https://geert hofstede.com/culture-geert-hofstede-gert-jan-hofstede/6d-model-of-national-culture/, accessed on May 30, 2017.

27. Hudson, D., 'Attachment Theory and Leader-follower Relationships', 2013, The Psychologist-Manager fournal, vol. 16, no. 3, pp. 147-159.

28. Jawahar, I.M. and Carr, D., 'Conscientiousness and Contextual Performance: The Compensatory Effects of Perceived Organizational Support and Leader-Member Exchange', 2007, fournal of Managerial Psychology, vol. 22, no. 4, pp. 330-349.

29. Jung, D.I. and Avolio, B. J., 'Effects of Leadership Style and Followers' Cultural Orientation on Performance in Group and Individual Task Conditions', 1999, The Academy of Management Journal, vol. 42, no. 2, pp. 208-218.

30. Kağıtçıbaşı, C., 'Individualism and Collectivism, in Berry, J.W., Segall, M.H. and Kağıtçıbaşı, C. (eds.), Handbook of Cross-cultural Psychology, Volume 3: Social Behavior and Applications, Needham Heights, MA: Allyn \& Bacon, 1997, pp. 1-49.

31. Kağıtçıbaşı, C. and Ataca, B., 'Value of Children and Family Change: A Three-decade Portrait from Turkey', 2005, Applied Psychology: An International Review, vol. 54, no. 3, pp. 317-337.

32. Kant, I., Critique of Practical Reason (translation by M. Gregor), Cambridge, UK: Cambridge University Press, 1997.

33. Khatib, T., 'Organizational Culture, Subcultures, and Organizational Commitment', Retrospective Theses and Dissertations, paper no. 11540, Iowa State University, 1996, [Online] available at http://lib.dr.iastate.edu/rtd/11540/, accessed on December 12, 2016.

34. Lamm, E., Gordon, J. and Purser, R.E., 'The Role of Value Congruence in Organizational Change', 2010, Organization Development fournal, vol. 28, no. 2, pp. 49-64.

35. Leong, L.Y.C. and Fischer, R., 'Is Transformational Leadership Universal? A Meta-Analytical Investigation of Multifactor Leadership Questionnaire Means Across Cultures', 2011, Journal of Leadership and Organizational Studies, vol. 18, no. 2, pp. 164-174.

36. Li, J., Furst-Holloway, S., Gales, L., Masterson, S.S. and Blume, B.D., 'Not All Transformational Leadership Behaviors Are Equal: The Impact of Followers' Identification with Leader and Modernity on Taking Charge', 2017, Journal of Leadership and Organizational Studies, vol. 24, no. 3, pp. 318-334.

37. Mansur, J.A., 'On Paternalistic Leadership Fit: Exploring Cross-cultural Endorsement Leader-follower Fit, and the Boundary Role of Organizational Culture', Unpublished Doctoral Thesis, Pesquisa Administration Academy, 2016, [Online] available at http://bibliotecadigital.fgv.br/dspace/handle/10438/15580, accessed on May 30, 2017.

38. Mason, C., Griffin, M. and Parker, S., 'Transformational Leadership Development: Connecting Psychological and Behavioral Change', 2014, Leadership and Organization Development Journal, vol. 35, no. 3, pp. 174-194. 
39. Mobasseri, S., Goldberg, A. and Srivastava, S.B., 'What Is Cultural Fit? From Cognition to Behavior (and Back)', in Brekhus, W.H. și Ignatow, G., Oxford Handbook of Cognitive Sociology, New York: Oxford University Press, 2019, pp. 305-340.

40. Morris, M.W. and Fu, H.Y., 'How Does Culture Influence Conflict Resolution? A Dynamic Constructivist Analysis', 2001, Social Cognition, vol. 19, no. 3, pp. 324-349.

41. Nelson, M.R. and Shavitt, S., 'Horizontal and Vertical Individualism and Achievement Values: A Multimethod Examination of Denmark and the United States', 2002, fournal of Cross-Cultural Psychology, vol. 33, no. 5, pp. 439-458.

42. Niemeyer, J.R.L. and Cavazotte, F.S.C., 'Ethical Leadership, Leader-Follower Relationship and Performance', 2016, Revista de Administrção Mackenzie, vol. 17, no. 2, pp. 67-92.

43. Nordlund, A., 'Values, Attitudes, and Norms: Drivers in the Future Forests Context', Future Forests Working Report, Umeå University, Umeå, 2009, [Online] available at https://www. slu.se/globalassets/ew/org/centrb/f-for/pdf/2009-nordlund-values-attitudes-and-norms. pdf, accessed on May 30, 2017.

44. Oyserman, D., Coon, H.M. and Kemmelmeier, M., 'Rethinking Individualism and Collectivism: Evaluation of Theoretical Assumptions and Meta-analyses', 2002, Psychological Bulletin, vol. 128, no. 1, pp. 3-72.

45. Özbek, M.F., 'The Relationships of Horizontal and Vertical Individualism and Collectivism and Money Ethic: A Comparative Study of Turkish and Kyrgyz University Students', 2010, Anadolu University fournal of Social Sciences, vol. 10, no. 3, pp. 23-42.

46. Pellegrini, E.K. and Scandura, T.A., 'Leader-member Exchange (LMX), Paternalism and Delegation in the Turkish Business Culture: An Empirical Investigation', 2006, fournal of International Business Studies, vol. 37, no. 2, pp. 264-279.

47. Sarros, J., Gray, J. and Desten, I., 'Leadership and Its Impact on Organizational Culture', 2002, International fournal of Business Studies, vol. 10, no. 2, pp. 1- 26.

48. Schwartz, S.H., 'An Overview of the Schwartz Theory of Basic Values', 2012, Online Readings in Psychology and Culture, vol. 2, no. 1, https://doi.org/10.9707/2307-0919.1116.

49. Shavitt, S., Johnson, T.P. and Zhang, J., 'Horizontal and Vertical Cultural Differences in the Content of Advertising Appeals', 2011, Journal of International Consumer Marketing, vol. 23 no. 3-4, pp. 297-310.

50. Singelis, T.M., Triandis, H.C., Bhawuk, D. and Gelfand, M.L., 'Horizontal and Vertical Dimensions of Individualism and Collectivism: A Theoretical and Measurement Refinement', 1995, Cross-Cultural Research, vol. 29, no. 3, pp. 240-275.

51. Snyder, B., 'Half of Us Have Quit Our Job because of a Bad Boss', 2015, [Online] available at http://fortune.com/2015/04/02/quit-reasons/, accessed on May 30, 2017.

52. Taras, V., Kirkman, B.L. and Steel, P., 'Examining the Impact of Culture's Consequences: A Three-Decade, Multilevel, Meta-Analytic Review of Hofstede's Cultural Value Dimensions', 2010, Journal of Applied Psychology, vol. 95, no. 3, pp. 405-439.

53. Trafimow, D., Triandis, H.C. and Goto, S.G., 'Some Tests of the Distinction between the Private and the Collective Self', 1991, Journal of Personality and Social Psychology, vol. 60, no. 5, pp. 649-655.

54. Triandis, H.C. and Gelfand, M., 'Converging Measurement of Horizontal and Vertical Individualism and Collectivism', 1998, Journal of Personality and Social Psychology, vol. 74, no. 1, pp. 118-128. 
55. Tushman, M.L. and O'Reilly III, C.A., Winning Through Innovation: A Practical Guide to Leading Organizational Change and Renewal, Boston, MA: Harvard Business School Press, 1997.

56. Uhl-Bien, M. and Maslyn, M., 'Paternalism as a Form of Leadership: Differentiating Paternalism from Leader-member Exchange', Paper presented at the meeting of the Academy of Management, Honolulu, Hawaii, August, 2005.

57. Wasti, S.A. and Eser Erdil, S., 'The Turkish Adaptation of Self Construal and INDCOL Scales', 2007, Yönetim Araştırmaları Dergisi, vol. 7, pp. 39-66.

58. Wilderom, C., van den Berg, P. and Wiersma, U., 'A Longitudinal Study of the Effects of Charismatic Leadership and Organizational Culture on Objective and Perceived Corporate Performance', 2012, The Leadership Quarterly, vol. 23, no. 5, pp. 835-848. 